\title{
California Groundwater Ambient Monitoring and Assessment (GAMA) Program Priority Basin Project: Shallow Aquifer Assessment
}

\section{What is the GAMA Priority Basin Project (GAMA-PBP)?}

The GAMA-PBP is a comprehensive assessment of statewide groundwater quality in California. The first phase of the GAMA-PBP focused on assessing groundwater resources used for public drinkingwater supplies. More than 2,000 public-supply wells were sampled between 2004 and 2012 for this initial phase. The second phase is focused on assessing groundwater resources used by domestic well owners for drinking-water supplies. The U.S. Geological Survey began sampling wells for this second phase in 2012. Domestic wells typically are drilled to shallower depths in the groundwater system than public-supply wells. Shallow groundwater may respond more quickly and be more susceptible to contamination from human activities at the land surface than the deeper aquifers.

The California State Water Resources Control Board's (SWRCB) GAMA-PBP was developed in response to the Groundwater Quality

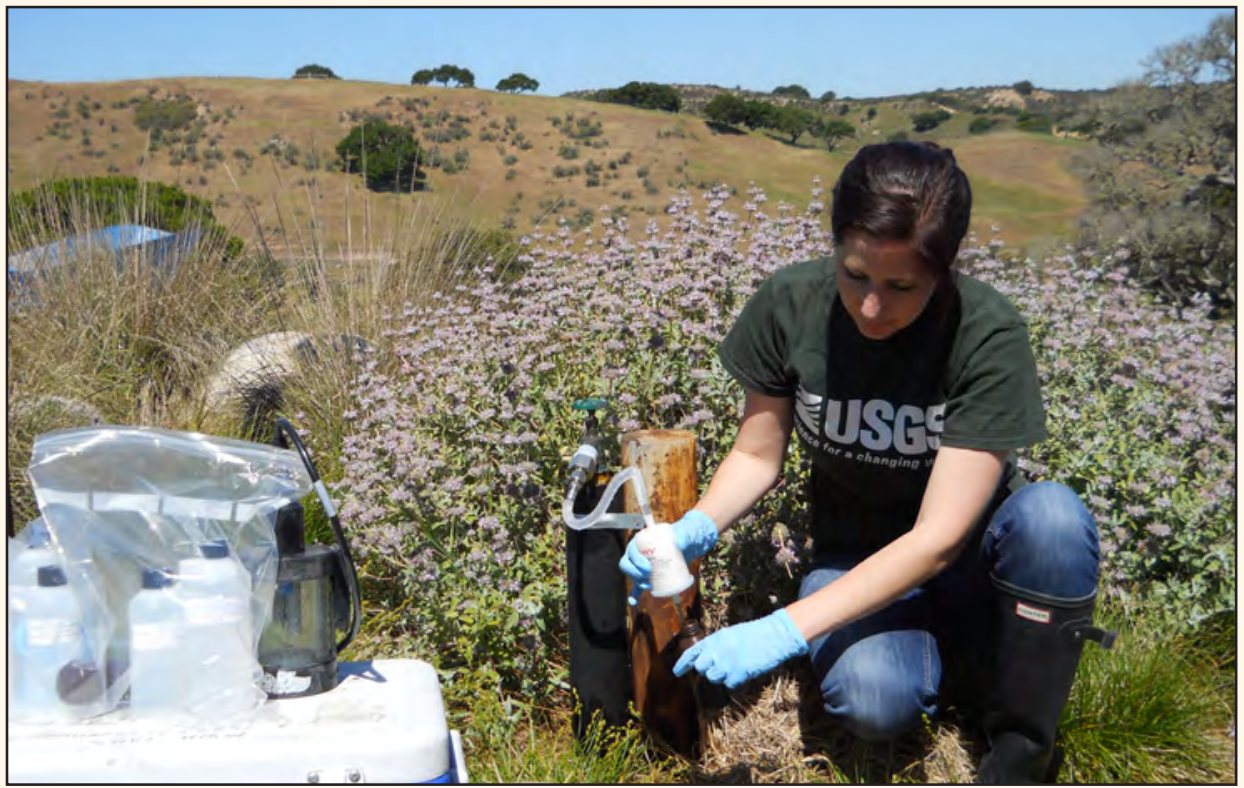

Monitoring Act of 2001 (Water Code sections 10780-10782.3): a public mandate to assess and monitor the quality of groundwater resources used for drinking-water supplies, and to increase the availability of information about groundwater quality to the public. The U.S. Geological Survey (USGS) is conducting the GAMAPBP, in cooperation with the SWRCB and the Lawrence Livermore National Laboratory.

Stewardship of California's groundwater resources is a responsibility shared between well owners, communities, and the State. Participants and collaborators in the GAMA-PBP include Regional Water Quality Control Boards, Department of Water Resources, Department of Public Health, local and regional groundwater management entities, county and local water agencies, community groups, and private citizens. Well-owner participation in the GAMA-PBP is entirely voluntary.

Well sampling in the Salinas Valley, California

\section{What Will Participants Gain from the GAMA- PBP Shallow Aquifer Assessment?}

The project will provide many benefits to State, local, and community participants and to individual well owners. It will:

- Provide well owners with information about the constituents in their water;

- Establish baseline groundwater quality for comparison with future conditions;

- Identify emergent constituents in groundwater;

- Identify areas of California where domestic households rely upon poor-quality groundwater for drinking supply;

- Improve understanding of local, regional, and statewide hydrogeology;

- Produce groundwater-quality reports for each study area;

- Provide new information for local, regional, and statewide groundwater programs to help manage groundwater resources;

- Provide new data for the SWRCB's GeoTracker GAMA publicly accessible online database; and

- Compare water quality in the shallow and deeper aquifer systems. 


\section{GAMA Priority Basin Project Shallow Aquifer Assessment Study Design}

The locations of domestic wells across California were identified from well-drillers' logs and U.S. Census data, and the areas of the State with the greatest densities of households that rely on domestic wells were prioritized for sampling for this project. The high-priority areas (see figure below) will be grouped into study units. Sixty to 120 domestic wells will be sampled in each study unit to provide a spatially unbiased assessment of the groundwater quality in the shallow aquifer systems. Domestic wells typically tap shallower parts of the aquifer system than do the public-supply wells sampled in the previous phase of the GAMA PBP. Shallow parts of the aquifer system may be more susceptible to contamination from human activities at the land surface, and shallow groundwater typically responds more rapidly to landsurface activities than the deeper systems.

Two types of assessments will be conducted for each study unit:

Status: the assessment of current groundwater quality and

Understanding: the assessment of natural and human factors that affect groundwater quality.

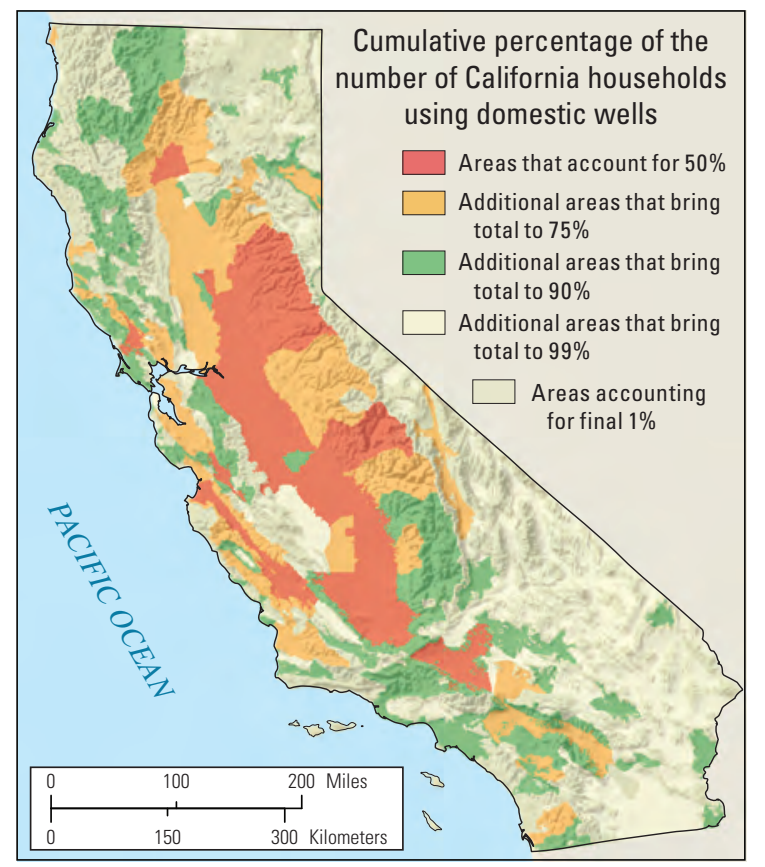
GAMA-PBP will combine existing water-quality data (such as data from the SWRCB's Domestic Well Project) with new data collected for this project. Samples will be analyzed for a large suite of chemical constituents, including nutrients, human-made organic constituents, naturally occurring trace elements, and tracers used to help identify the source and age of the sampled groundwater (table 1).

\section{Reporting Results}

The GAMA-PBP provides new

Table 1. List of analytes.

\section{Sampled constituents}

\section{Why constituents are of interest}

\section{Specific conductance}

Alkalinity, pH, and dissolved oxygen

Temperature

Major and minor ions

Nutrients

Trace elements

Volatile organic compounds (VOCs) Methyl tert-butyl ether (MTBE)

Pesticides

$N$-Nitrosodimethylamine (NDMA).

Perchlorate $\left(\mathrm{ClO}_{4}{ }^{-}\right)$

Isotopes, radioactivity

Tritium $\left({ }^{3} \mathrm{H}\right)$

Noble gases

Stable isotopes $\left(\delta^{18} 0, \delta D\right)$

Radon (Rn)
The ability of a water sample to transmit an electrical current; related to the salinity of the water

The cation and anion activity and oxygen concentration in water. These properties affect the mobility of dissolved chemical compounds Temperature can influence the concentration of dissolved gases (such as oxygen, nitrogen, carbon dioxide) in water Naturally occurring elements that influence water quality

Elevated concentrations of nutrients (such as nitrogen, phosphorous) can degrade water quality Naturally occurring elements that help define water characteristics and affect water quality Include human-made compounds such as solvents, gasoline additives, and organic synthesis products that can degrade water quality A compound added to gasoline to improve air quality. At high concentrations, it can degrade water quality Used to control weeds, insects, and other pests and can degrade water quality

A byproduct of water treatment from the reaction of dimethylamine and chloramines which can degrade water quality Inorganic constituent found in rocket fuel, fireworks, and flares, and also occurs naturally at low concentrations in groundwater. At high concentrations, it can degrade water quality

Naturally occurring atoms and radioactivity used to track water movement; may degrade water quality at high concentrations Isotope of hydrogen used to identify water recharged since 1952

Dissolved gases used to trace groundwater movement, for chronology, and to study climate change Naturally occurring isotopes of oxygen and hydrogen used to track water through the hydrologic cycle A naturally occurring radioactive gas which, at high levels, can cause health problems such as lung cancer 